\title{
Introduction to the special section on the public finance - growth nexus
}

\author{
ZSOLT DARVAS $^{1,2 *}$
}

${ }^{1}$ Bruegel, Brussels, Belgium

${ }^{2}$ Corvinus University of Budapest, Hungary

Received: October 27, 2020 • Accepted: October 27, 2020

(C) 2020 The Author(s)

The deep economic contraction triggered by COVID-19 results in large budget deficits and ballooning public debts, which could pose serious fiscal challenges to several countries. COVIDrelated challenges amplify the difficulty of long-standing public finance problems, such as the sustainability of European welfare systems in the midst of ageing populations and the difficulties of taxing in a globalised world, where rich people and multinational companies hide their income and wealth through complex financial structures involving several countries. It is therefore even more important that scarce public resources are collected and spent well.

The four articles in this special section of Society and Economy address different aspects of the nexus between public finance structure and economic growth. The first versions of these papers were prepared for the Budapest Public Finance Seminar 2019 on 'Growth implications of state budget income and expenditure structure', held in Budapest, Hungary on 23 May 2019, and organised by the Hungarian State Treasury. The initial conference papers were developed into academic articles and were subject to the same level of peer review as any other article in Society and Economy. The order of the articles in this special issue reflects the order they were presented at the conference.

It was a great privilege for me to deliver the keynote speech at the conference in which I focused on some big picture issues, drawing on a large body of existing research. The specific aspect I emphasise is the income distributional impacts of public finance structure and effectiveness, in addition to aggregate economic growth impacts. Both the academic and policy discussions of distributional issues became more prominent in the past decade. My main argument for a fair distribution of income as reflected in low-income inequality is that income inequality typically implies inequality of opportunity. While 'fairness' is a complex concept, whatever definition is adopted, it cannot be regarded as 'fair' if two persons reach different outcomes when they have the same talents and make the same effort, just because of their different family backgrounds. My analysis of public finance structures of European Union

\footnotetext{
${ }^{*}$ Corresponding author. E-mail: zsolt.darvas@uni-corvinus.hu.
} 
countries shows large diversity, suggesting that there is no consensus on the main features of an effective, efficient and fair system in policy circles. I therefore review academic works and provide recommendations on how to alter the composition of taxing and spending in order to boost growth and reduce inequalities.

Salvador Barrios presents an exciting examination of the growth impact of tax reforms from a methodological perspective and then illustrates it by analysing the growth impact of a hypothetical change from the current flat personal income tax (PIT) rates to progressive taxes in Central and Eastern European (CEE) countries. Barrios argues that tax reforms affect incentives and the behaviour of people, which have feedbacks on economic growth. The standard methodology used in the literature, cross-country growth regressions, cannot capture such behavioural changes and suffer from various identification and endogeneity issues, and hence could lead to wrong conclusions and biased policy recommendations. He advocates the use of the dynamic scoring approach combining microsimulation and macro models, which can also account for the second-round effects of tax reforms. His example analysing a hypothetical reversal to progressive tax regimes in CEE countries with a flat tax systems finds a small but positive impact when using the dynamic scoring method, while the less-reliable traditional growth regressions would suggest adverse growth effects. Hence, his result contrasts the views of flat tax advocates.

Desislava Stoilova and Nikolay Patonov produced an interesting case study of Bulgaria about public finance structure and economic growth. By using a regression technique, they find that taxation matters more for growth than public spending. One of their explanations for the negligible role of public spending is weak domestic supply. If that is the case, more public spending could just lead to more imports and a higher current account deficit without stimulating growth. The other explanation is corruption, which is associated with public investment. Corruption can lead to wasteful and inefficient investments. Interestingly, while a large body of literature finds that public investment is growth-enhancing, at least in developed countries, Stoilova and Patonov cite some works studying data from developing countries which conclude that public investment is bad for growth. Hence, unfortunately, it seems that Bulgaria is more similar to developing countries than to developed countries in terms of the efficiency of public investment and their findings call for strong actions against corruption and for improving the efficiency of public investment. Since a large share of Bulgarian public investment is financed by European Union structural funds, such efficiency improvement is a common European interest.

Gábor Kutasi and Ádám Márton prepared an insightful analysis of the long-term impacts of public expenditures on growth. Instead of focussing on total expenditures, which could blur the impacts of different sub-categories, they analyse ten main public spending areas according to the Classification of the Functions of Government (COFOG) categorisation. They consider data from 25 European countries between 1996 and 2017, and apply three different econometric estimation methods to study robustness. The main novelty of their paper is the analysis of delayed impacts, since they argue that certain public spending items are unlikely to influence economic development immediately. Their model allowing delayed effects confirms the positive growth impacts of public education and health spending. Interestingly, while COFOG does not allow studying the impact of public research and development spending and public investment two spending areas found to have positive impact on growth in earlier research - their result does not confirm that the closest category of 'economic affairs' has a positive impact. For the remaining spending categories their results are either ambiguous or even suggest negative 
impacts on growth and thus their article casts doubt about the growth-friendliness of most public spending.

These four studies provide rich insights into the nexus between public finance structure and economic growth in a European context, and provide an important call for more comparative studies.

Open Access. This is an open-access article distributed under the terms of the Creative Commons Attribution-NonCommercial 4.0 International License (https://creativecommons.org/licenses/by-nc/4.0/), which permits unrestricted use, distribution, and reproduction in any medium for non-commercial purposes, provided the original author and source are credited, a link to the CC License is provided, and changes - if any - are indicated. 